\title{
Avaliação Financeira do Sequestro de Carbono na Serra de Baturité, Brasil, 2012
}

\author{
Ana Milena Plata Fajardo ${ }^{1}$, Romano Timofeiczyk Junior ${ }^{1}$ \\ ${ }^{1}$ Departamento de Engenharia Florestal, Universidade Federal do Paraná - UFPR, Curitiba/PR, Brasil
}

\begin{abstract}
RESUMO
Este estudo teve como objetivo quantificar a biomassa e o estoque de $\mathrm{CO}_{2}$ e avaliar a viabilidade econômica de geração de créditos de carbono na Área de Proteção Ambiental - APA da Serra de Baturité, Ceará. A quantificação da biomassa foi feita pelo método não destrutivo e foram avaliados financeiramente três mercados de carbono. O mercado regulado: Mecanismo de desenvolvimento limpo - MDL; e os mercados voluntários: Verified Carbon Stantard - VCS e o esquema de comércio de Emissões da Nova Zelândia - NZ ETS. Os critérios financeiros utilizados para a avaliação foram o Valor Presente Líquido (VPL) e a Taxa Interna de Retorno (TIR). Os resultados mostraram que a APA sequestra em média 84,63 MtCO2e. De acordo com os preços e custos do mercado para o ano 2012, os projetos florestais para sequestro de carbono podem gerar valor anual equivalente de $\mathrm{R} \$ 1.336 \mathrm{e}$ TIR de $21 \%$ por hectare, se vendido no mercado NZ ETS. No mercado VCS, a venda dos créditos gera VPL de R $\$ 2.138$ e TIR de $18 \%$. Entretanto, se os créditos forem comercializados no MDL, o VPL será de R\$ -702,5, concluindo-se que o projeto é viável nos mercados voluntários e inviável no mercado regulado.
\end{abstract}

Palavras-chave: mercado de carbono, floresta ombrófila, fluxo de caixa.

\section{Financial Feasibility of Carbon Sequestration in Serra de Baturité, Ceara state, Brazil in 2012}

\begin{abstract}
The aim of this study was to estimate the biomass and $\mathrm{CO}_{2}$ sink and evaluate the economic viability of the generation of carbon credits in the Environmentally Protected Area (EPA) of Serra de Baturité, Ceara state, Brazil. The assessment of aboveground biomass was estimated by the non-destructive method, and the economic criteria used to evaluate were the Net Present Value (VPL), Equivalent Annual Value (EAV) and Internal Rate of Return (IRR). The results show that the rainforest of the Serra de Baturite EPA sequestered $84.63 \mathrm{MtCO}_{2} \mathrm{e}$ and that, according to market prices and costs in 2012, forestry projects for carbon sequestration can generate an EAV of R\$1,336 (IRR: 21\%) per hectare if it is sold in the New Zealand Emissions Trading Scheme (NZ ETS) market, R\$2,138 (IRR: 18\%) if it is sold in the Verified Carbon Standard (VCS) market, and R - 702.5 if it is sold in the Clean Development Mechanism (CDM) regulated market. In short, the project is viable if carbon credits are sold in the voluntary markets, otherwise it is unviable.
\end{abstract}

Keywords: carbon credit, rainforest, cash flow. 


\section{INTRODUÇÃO}

Uma das maiores contribuições na mitigação das mudanças climáticas é o sequestro de carbono. O sequestro de carbono é um importante serviço ecossistêmico provido pelas florestas. A vegetação (árvores, arbustos e gramados), pelo processo de fotossíntese, absorve gás carbônico da atmosfera e, durante certo tempo, armazena carbono orgânico na planta e na biomassa da raiz. A finalidade do processo de sequestro de carbono é diminuir o acumulo de $\mathrm{CO}_{2}$ na atmosfera visando à diminuição do efeito estufa (Kulshreshtha et al., 2000). O sequestro florestal de carbono se consagrou a partir do Protocolo de Kyoto, em 1992, quando foram aprovados os mecanismos de redução de emissões do efeito estufa (Yu, 2004).

As serras úmidas cearenses representam ambientes de grande importância biológica e prioritários para conservação da biodiversidade no Brasil (Brasil, 2004). Na região, destaca-se o Maciço Residual de Baturité, que se configura como um território de exceção no contexto da quase absoluta semiaridez do Ceará. Sob o ponto de vista climático, na área serrana, a incidência de totais pluviométricos elevados (média de $1.500 \mathrm{~mm}$ anuais) permite incluí-la como uma das mais úmidas do estado e um dos mais importantes dispersores da drenagem que converge, em parte, para a região metropolitana de Fortaleza (Oliveira \& Araújo, 2005).

A Área de Proteção Ambiental - APA da Serra de Baturité localizada no centro-norte do Ceará representa uma área importante na consolidação de mecanismos de regulação do clima, assim como na redução de emissões de efeito estufa, uma vez que possui solos diversificados e recobertos pelas florestas ombrófila aberta, floresta estacional semidecidual e, nas porções de altitudes mais baixas, floresta estacional decidual (Brasil, 2004).

De acordo com Baalman \& White (2014), o sequestro de carbono florestal funciona como uma moeda ambiental que pode ser comercializada e vendida para países que estão obrigados a reduzir suas emissões. Esse processo de compra e venda de créditos de carbono florestais se dá a partir da verificação, monitoramento e reporte de projetos ligados a reflorestamentos, à redução de emissões de deflorestação e degradação florestal REDD e ao manejo florestal sustentável.
Segundo Stanley-Peters \& Gonzalez (2014), no ano 2013 a Ásia foi a região que mais vendeu créditos de carbono (21 MtCO2e), porém $70 \%$ dos créditos foram gerados por projetos de energia renovável. Enquanto isso, a América Latina foi a segunda colocada em volume de venda de créditos de carbono, com $19 \mathrm{MtCO} 2$ transacionadas. O maior projeto de América Latina foi o acordo bilateral entre o governo do Acre, Brasil, e o banco alemão KfW, que para o ano 2012 gerou 8 $\mathrm{MtCO} 2 \mathrm{e}$.

De acordo com a UNFCCC (2007), para que um projeto seja verificado e validado no mercado de créditos de carbono é necessário quantificar a biomassa florestal e o sequestro de carbono. A quantificação de biomassa florestal, conforme Salati (1994), divide-se em métodos diretos e indiretos. O método direto consiste em mensurações baseadas em árvores cortadas e seus componentes, que são separados e pesados. Os métodos indiretos se dividem em dois. O primeiro baseia-se em dados de inventário florestal, empregando-se fatores e equações de biomassa que transformam dados de diâmetro, altura ou volume em biomassa aérea. O segundo é baseado em imagens de satélite e em Sistema de Informações Geográficas (SIG).

Estimativas direitas da biomassa focadas em medições do inventário florestal por meio da colheita destrutiva são mais verificáveis e eficientes do que as estimativas indiretas (IPCC, 2006). Por outro lado, desenvolver relações alométricas é demorado e custoso, isso porque requer a colheita destrutiva de um grande número de árvores.

As técnicas de sensoriamento remoto têm sido amplamente utilizadas em estudos na área florestal, uma vez que é possível estimar parâmetros biofísicos, como biomassa, carbono e volume de madeira com base nas propriedades espectrais dos componentes da vegetação (Souza \& Ponzoni, 1998). Satélites ópticos como Landsat têm sido usados para estimar os estoques de carbono florestal, através do desenvolvimento de relações estatísticas entre as medições terrestres e índices de vegetação observados por satélite (Foody et al., 2003).

Com base nas estimativas de carbono florestais é possível determinar o faturamento obtido com a venda de créditos de carbono, calculado através da multiplicação do $\mathrm{CO}_{2}$ sequestrado pelo preço de mercado. De acordo com Stanley-Peters \& Yin (2013), o mercado de carbono não tem uma forma específica 
de pagamento, onde várias estruturas de contrato são admitidas. A mais reconhecida forma de pagamento é chamada Spot Transaction. Esse tipo de negociação é realizado após a verificação dos créditos. Os créditos são verificados no ano zero quando é apresentado o Project Design Documment, e após ser aprovado pelo standard, a venda tem duas opções: ex ante e ex post. Venda ex post significa que os créditos serão adquiridos após a redução das emissões de $\mathrm{CO}_{2}$. Ex ante significa que a venda se antecipa à futura geração de créditos (Baalman \& White, 2014).

Levando em consideração que o investimento florestal requer um montante significativo de capital, o qual fica imobilizado por longo período. Torna-se fundamental analisar as variáveis financeiras que influenciam a tomada de decisão de investimento em projetos de carbono florestal.

Nesse sentido, o artigo tem como objetivo principal avaliar três cenários de venda de créditos de carbono florestal na Serra de Baturité. Para isso é apresentada a quantificação do estoque de $\mathrm{CO}_{2}$ na área e a desagregação de custos e receitas do projeto para um horizonte temporal de 30 anos. A partir das estimativas do $\mathrm{CO}_{2}$ sequestrado na área e o fluxo de caixa, são analisados os critérios de decisão financeiros Valor Presente Líquido - VPL e Taxa Interna de Retorno - TIR.

\section{MATERIAL E MÉTODOS}

\section{1. Área de estudo}

As classes de solos predominantes na APA da Serra de Baturité são Latossolo Vermelho-Amarelo e Argissolo Vermelho-Amarelo. De acordo com Lima et al. (1997), os Latossolos Vermelho-Amarelo que ocorrem na serra de Baturité são solos normalmente profundos ou muito profundos (em média acima de 1,50 m), variando em função do relevo.

Tais características climáticas e geomorfológicas possibilitaram a evolução de uma complexa cobertura vegetal, com atributos gerais de floresta tropical úmida que se distribui por duas grandes unidades de cobertura vegetal: a Floresta Ombrófila Aberta (mata úmida), que ocupa as altitudes mais altas, e a Floresta Estacional Semidecidual (mata seca), a qual predomina nos setores situados entre 400 e $600 \mathrm{~m}$ de altitude (Lima et al., 1997).

Segundo dados de Oliveira \& Araújo (2005), o levantamento fitossociológico em quatro fragmentos de vegetação da floresta ombrófila da APA da Serra de Baturité apresenta os seguintes resultados, considerando Densidade, Área basal, Diâmetro a altura do peito - DAP e Altura (Tabela 1).

A floresta do sítio Taveiras foi a que apresentou menos densidade (735 ind/ha) e maior DAP $(13,4 \mathrm{~cm})$ de todos os quatro levantamentos realizados na Serra de Baturité. Portanto, de todas as áreas amostradas, essa vegetação parece ser a que apresenta as plantas mais grossas, por ser a de maior área basal total, e fisionomia mais aberta, por ter a menor densidade. A mata úmida do sítio Arvoredo (1.215 ind/ha), situada nas altitudes mais elevadas da serra (935 metros acima do nível do mar - m.a.n.m.), embora tenha quase o dobro da densidade encontrada no sítio Taveiras (735 ind/ha), por apresentar as plantas mais finas, resulta no menor DAP médio $(10,5 \mathrm{~cm})$ (Oliveira \& Araújo, 2005).

\subsection{Determinação da biomassa}

Foram analisados os métodos diretos e indiretos da estimação de sequestro de carbono conforme Salati (1994). A técnica de sensoriamento remoto foi descartada já que a floresta ombrófila é de grande

Tabela 1. Descritores fisionômicos da floresta ombrófila na Serra de Baturité

Table 1. Physiognomic Aspect of Rainforest at Serra de Baturité.

\begin{tabular}{ccccccc}
$\begin{array}{c}\text { Sítios } \\
\text { amostrados }\end{array}$ & $\begin{array}{c}\text { Altitude da } \\
\text { vertente } \\
\text { (m.a.n.m.) }\end{array}$ & $\begin{array}{c}\text { Área } \\
\text { amostrada } \\
\text { (ha) }\end{array}$ & $\begin{array}{c}\text { Densidade } \\
(\mathbf{i n d} / \mathbf{h a})\end{array}$ & $\begin{array}{c}\text { Área basal } \\
\left(\mathbf{m}^{\mathbf{2}} \mathbf{h a}\right)\end{array}$ & $\begin{array}{c}\text { DAP } \\
\text { médio } \\
(\mathbf{c m})\end{array}$ & $\begin{array}{c}\text { Altura média } \\
(\mathbf{m})\end{array}$ \\
\hline Arvoredo & 935 & 0,66 & 1215 & 14,1 & 10,5 & 9 \\
Lagoa & 940 & 0,46 & 1741 & 31,2 & 12,9 & 8,3 \\
Sinimbu & 695 & 0,5 & 1597 & 25,5 & 11,8 & 9 \\
\hline Taveiras & 600 & 1,08 & 735 & 15,5 & 13,4 & 8 \\
\hline
\end{tabular}

Fonte: Oliveira \& Araújo, 2005. 
diversidade florística, fisionômica e fenológica, tornando complexa a determinação da biomassa.

Considerou-se o método não destrutivo baseado em estimações de parâmetros provenientes de inventários florestais o que se adapta melhor à complexidade e às condições florísticas da APA da Serra de Baturité. Logo após a determinação dos parâmetros, foi usada a equação de Brown et al. (1989), por ser a mais robusta $\left(\mathrm{R}^{2}=0,97\right)$. Essa Equação (1), também utilizada por Watzlawick (2003), para floresta ombrófila de Mata Atlântica, e por Fernandes et al. (2008), é descrita como:

$$
\boldsymbol{Y}=\exp \left[-3,1141+0,9719 * \operatorname{In}\left(\boldsymbol{d a p}^{2 * h t o t}\right)\right]
$$

em que: $\mathrm{Y}=$ Biomassa; dap = diâmetro à altura do peito; htot $=$ altura total.

Os estoques de carbono foram calculados considerando-se que representam $50 \%$ da biomassa seca (Fernandes et al., 2008). Para Fernandes et al. (2008), a estimativa dos estoques de carbono significa, de um modo geral, a quantidade que foi retirada da atmosfera e que se encontra na biomassa aérea, na forma de carbono orgânico. Para se encontrar o volume de estoque de $\mathrm{CO}_{2}$, considerou-se que 1 Megagrama $(\mathrm{Mg})$ de carbono corresponde a 3,67 $\mathrm{Mg}$ de $\mathrm{CO}_{2}$ (Ronquim, 2007). Consequentemente, multiplica-se o valor total de carbono em Megagramas por 3,67 e obtém-se o valor de $\mathrm{CO}_{2}$ retirado da superfície terrestre.

Ressalta-se que a equação não foi ajustada para a área. De acordo com Brown (2002), as relações alométricas específicas não são necessárias para gerar estimativas confiáveis de estoques de carbono florestal. Agrupar todas as espécies em conjunto e utilizar relações alométricas generalizadas, estratificadas por tipo de floresta ou zona ecológica, é altamente eficaz para os trópicos porque o diâmetro à altura do peito explica mais de 95\% da variação no estoque de carbono acima do solo da floresta tropical, mesmo em regiões muito diversas (Brown, 2002).

\subsection{Análise financeira}

Simioni \& Hoeflich (2006) destacam que na área florestal o investidor deve decidir o quanto produzir (o que está diretamente relacionado com a área), como produzir (o que se reflete no manejo florestal) e qual o destino de produto.
No que se refere ao quanto produzir ou área necessária de plantio, ela foi estimada considerando-se a fixação de $150.000 \mathrm{Mg}$. $\mathrm{Ha}^{-1}$, que corresponde ao tamanho médio de projetos existentes no âmbito do MDL. Assim, com base nessa fixação e na capacidade de geração de créditos de carbono de cada cenário, estimou-se a área necessária em hectares (Equação 2):

Área $=\frac{150.000 \mathrm{tCO} 2 \cdot \mathrm{ano}-1}{84,63 \mathrm{tCO} 2 \mathrm{~h}-^{1}}=1.772,42 \mathrm{ha}$

Assim, a área destinada para que o projeto sequestre 150.000 tCO2. ano $^{-1}$ deve ser de 1.773 hectares.

Sobre como produzir, se considera os custos do manejo florestal sustentável para um hectare na floresta ombrófila, de acordo com CI Florestas (2011). Finalmente, o destino do produto é a venda de créditos de carbono.

\subsection{Fluxo de caixa}

O fluxo de caixa simboliza as estimativas de custos e receitas de recursos monetários em certo projeto produtivo ao longo do tempo. A diferença entre os custos e as receitas representa o resultado líquido do fluxo de caixa (Santos, 2001). Neste estudo elaborou-se um fluxo de caixa contendo os principais custos e receitas. Foi determinado o horizonte de planejamento do projeto em 30 anos, porque representa o tempo mínimo para que a proposta de Manejo Sustentável de Florestas seja válida no âmbito das recomendações do IPCC (2006).

\subsection{Receitas: mercado de carbono}

Para este estudo foram considerados três mercados ou standards de verificação e venda de créditos de carbono. O mercado VCS, por ser o maior mercado em volume de transações de créditos de carbono (Stanley-Peters \& Yin, 2013), sendo que depois da categoria de energias renováveis o manejo florestal sustentável, é a categoria com maior número de projetos transacionados no ano 2012, com 24 milhões de $\mathrm{tCO}_{2}$ O mercado NZ ETS foi escolhido porque o setor florestal foi a primeira categoria a ser criada (desde 2008), devido à grande importância que o setor florestal tem nas obrigações de redução de emissões de gases de efeito estufa (Ministry for the Environment, 2013). Finalmente foi escolhido o mercado MDL por ser a 
primeira instituição a ser criada depois do Protocolo de Kyoto e por ser mercado regulado.

O mercado de Mecanismo de Desenvolvimento Limpo (MDL) fechou o ano de 2012 ao preço de US\$ 1,00 , equivalente a $R \$ 2,20$. O mercado de emissões da Nova Zelândia (NZ ETS) apresentou o preço mais alto do mercado no ano 2012, com valor de US\$ 8,80 , equivalentes a $R \$ 19,36$. O Mercado Voluntário (VCS), o maior mercado em relação ao volume de milhões de toneladas de dióxido de carbono (MtCO2e) transacionadas, apresentou no final de 2012 preço de US\$ 7,00 (Stanley-Peters \& Yin, 2013), o que equivale a $\mathrm{R} \$ 15,4$.

Para este trabalho considerou-se a venda ex ante de créditos, o que significa que depois do ano zero (após aprovação de PDD), é creditada a primeira receita. Após o monitoramento e verificação, a cada cinco anos são vendidos novos créditos. $O$ projeto expira no final do período de crédito registrado ( 30 anos no caso de manejo florestal sustentável) (Singh, 2009).

\subsection{Custos}

$\mathrm{Na}$ análise financeira ou gerenciamento da atividade são considerados os custos totais de produção. Isto é, custos fixos, custos variáveis, custos de transação e custos de oportunidade (Graça et al., 2000). Os custos totais foram apresentados por hectare.

Os custos avaliados na análise econômica estão relacionados às fases de implantação e manutenção do projeto de um hectare de manejo florestal sustentável (MFS). Conforme a CI Florestas (2011), um hectare em MFS precisa no seu primeiro ano: construção da cerca, roçada, combate a formigas, adubação. Calcularam-se também os custos de transação de obter a verificação dos créditos sequestrados, por hectare.

\subsection{Custos de transação}

Os custos de transação referem-se ao tempo, esforço e recursos necessários para procurar, iniciar, negociar e concluir um acordo (Lile et al., 1998). De acordo com Galik \& Jackson (2009), os custos de transação em projetos de carbono florestal referem-se aos custos de validação e verificação. A verificação é oferecida por algumas organizações, sendo as mais destacadas a Aliança para o Clima, Comunidade e Biodiversidade - CCBA e os Padrões de Carbono Verificado - VCS.
Segundo Pearson et al. (2014), na América do Sul, o custo de validação e verificação é em média USD \$70.000 para projetos de manejo florestal sustentável na América Latina.

\subsection{Taxa de desconto}

Segundo Lima et al. (1997), as taxas de desconto tradicionalmente usadas em projetos florestais costumam variar entre $6 \%$ a $12 \%$ ao ano. Portanto, decidiu-se adotar uma taxa de desconto real de $10 \%$ ao ano, conforme as recomendações do Centro de Estudos Integrados sobre o Meio Ambiente e Mudanças Climáticas do Ministério do Meio Ambiente em documento publicado (Brasil, 2004) que trata da Proposta Revisada de Critérios e Indicadores de Elegibilidade para a Avaliação de Projetos no Mercado MDL no Brasil.

\subsection{Métodos de análise de investimentos}

Após a obtenção do fluxo de caixa contendo as entradas e saídas monetárias ao longo do horizonte de planejamento, utilizaram-se ferramentas da engenharia econômica para avaliação da rentabilidade do manejo. Para tanto, foram utilizados os métodos do Valor Presente Líquido (VPL) e a Taxa Interna de Retorno (TIR).

De acordo com Rezende \& de Oliveira (2001), o VPL pode ser expresso pela seguinte fórmula (Equação 3):

$V P L=\sum_{j=0}^{n} R j(1+i)^{-j}-\sum_{J=0}^{n} C j(1+i)^{-j}$

em que: $\mathrm{Rj}=$ Receitas do período de tempo $\mathrm{j}$ considerado; $\mathrm{Cj}=$ Custos do período de tempo $\mathrm{j}$ considerado; $\mathrm{n}=$ Duração do projeto em anos ou em número de períodos de tempo; $\mathrm{i}$ = Taxa anual de juro, expressa de forma decimal.

Segundo Rezende \& de Oliveira (2001), a TIR pode ser expressa pela fórmula (Equação 4):

$T I R=\sum_{j=0}^{n} R j(1+i)^{-j}-\sum_{j=0}^{n} C j(1+i)^{-j}=0$

em que: $\mathrm{Rj}$ = Receitas do período de tempo $\mathrm{j}$ considerado; $\mathrm{C}$ = Custos do período de tempo $\mathrm{j}$ considerado; $\mathrm{n}=$ Duração do projeto em anos ou em número de períodos de tempo. 


\section{RESULTADOS E DISCUSSÃO}

\subsection{Cálculo da biomassa na floresta ombrófila}

A estimativa final de biomassa e do estoque de carbono para a floresta ombrófila aberta primária é apresentada na Tabela 2. Observa-se que a biomassa média é igual a 45,99 Mg.h ${ }^{-1}$. O estoque de carbono médio obtido foi de $23 \mathrm{Mg} . \mathrm{h}^{-1}$. Consequentemente, o valor médio do $\mathrm{CO}_{2}$ retirado da atmosfera foi 84,63 Mg.h ${ }^{-1}$. A seguir se apresentam os valores de carbono de biomassa aérea e $\mathrm{CO}_{2}$ equivalentes para as quatro zonas amostradas (Tabela 2).

Comparando com outros biomas, a média da captura de carbono para uma área de bioma cerrado é de $36,33 \mathrm{Mg}^{*} \cdot$ ha $^{-1}$ (Batista \& Bueno, 2010). Por outro lado, Saldarriaga et al. (1988), em um estudo sobre o desenvolvimento sucessional na região amazônica, encontrou que o estoque de $\mathrm{CO}_{2}$ do fuste em quatro povoamentos de florestas maduras era de $286 \mathrm{Mg}^{\star} \cdot \mathrm{ha}^{-1}$.

O estoque de $\mathrm{CO}_{2}$ acumulado na Serra de Baturité não é tão alto se comparado com outras estimativas feitas no bioma Mata Atlântica. De acordo com Lacerda et al. (2009), a floresta ombrófila de Ibaté, São Paulo, atinge

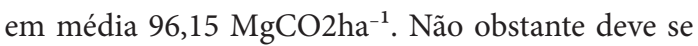
lembrar que a área de estudo é uma exceção no cenário semiárido do Nordeste de Brasil

\subsection{Analise financeira}

Considerando-se os investimentos incorridos em cada hectare de floresta, o custo investido e as receitas por hectare encontram-se na Tabela 3. Os cenários MDL, NZ ETS e VCS apresentam uma diferença fundamental na fonte de receitas. $O$ mercado MDL apresenta receitas de R 187 por hectare. O mercado de NZ ETS, por ser o mais alto em termos de preço, apresenta uma receita de R $\$ 1.638$ por hectare. O mercado VCS, com preço de $\mathrm{R} \$ 15,4 \mathrm{Mg}^{\star} \cdot \mathrm{h}^{-1}$, apresenta receitas de $\mathrm{R} \$ 1.300 / \mathrm{ha}$, colocando-se em uma posição intermediária em relação aos outros dois cenários avaliados. Segundo os cálculos, o projeto necessita, no ano de implantação (ano zero), de $\mathrm{R} \$ 933$ por hectare, sendo a construção da cerca e o custo de transação os fatores mais altos do fluxo de caixa ( $\mathrm{R} \$ 520$ e $\mathrm{R} \$ 111$ por hectare, respetivamente).

Importante ressaltar que a quase totalidade dos custos incorre no primeiro ano. Verifica-se também que os custos de monitoramento incorrem a cada cinco anos, após aprovação pelo standard de mercado, são creditadas as receitas.

Os critérios de avaliação de projetos (VPL e TIR) usados na análise econômica dos três cenários, sob uma taxa de desconto de $10 \%$ a.a. e um período de 30 anos, demonstraram que os cenários NZ ETS e VCS são economicamente viáveis. O projeto MDL demonstrou ser economicamente inviável, já que tanto VPL e VAUR são negativos e a TIR é indefinida. A TIR dos projetos NZ ETS e VCS apresentou valores maiores do que a taxa mínima de atratividade, o que torna os projetos viáveis. O cenário VCS se posiciona no nível intermédio de rentabilidade se comparado com os outros dois cenários e, além disso, o VCS é um mercado seguro e tem sido historicamente o maior mercado em relação ao volume de transações de emissões. O mercado voluntário (VCS) apresentou um crescimento altíssimo no ano 2012, atribuído ao aumento de $500 \%$ na fatia de mercado de projetos de REDD, devido ao seu reconhecimento formal no âmbito internacional e aprovação de metodologias com poucos requerimentos para os projetos.

O mercado do MDL apresentou inviabilidade, atribuída ao baixo preço de mercado ( $\mathrm{R} \$ 2,2)$. A abrupta queda dos preços do mercado na Europa nos últimos anos influenciou a demanda de créditos de carbono, ocasionando uma redução dos volumes vendidos e um estancamento no fluxo de transações. Embora alguns políticos e nações estejam receosos em inverter créditos de carbono, várias companhias estão voluntariamente

Tabela 2. Valores médios de biomassa, estoque de carbono e $\mathrm{CO}_{2}$ aéreos.

Table 2. Biomass, Capture Carbon and Capture Dioxide Carbon average value.

\begin{tabular}{|c|c|c|c|}
\hline Localização & Biomassa $\left(\mathrm{Mg}^{\star} \cdot \mathrm{h}^{-1}\right)$ & Estoque de C $\left(\mathrm{Mg}^{\star} \cdot \mathrm{h}^{-1}\right)$ & Estoque de $\mathrm{CO}_{2}\left(\mathrm{Mg}^{\star} \cdot \mathrm{h}^{-1}\right)$ \\
\hline Arvoredo & 36,31 & 18,15 & 66,62 \\
\hline Lagoa & 50,07 & 25,04 & 91,88 \\
\hline Sinimbu & 45,56 & 22,78 & 83,58 \\
\hline Taveiras & 52,02 & 26,01 & 96,45 \\
\hline Média & 45,99 & 23,00 & 84,63 \\
\hline
\end{tabular}


internalizando o preço da redução de emissões das suas atividades econômicas. Enquanto o mercado regulado se vê afetado pelos baixos preços, o mercado voluntário continua em crescimento (Stanley-Peters \& Yin, 2013).

$\mathrm{Na}$ Tabela 4 é comparando o projeto de sequestro de carbono na floresta ombrófila da Serra de Baturité com outros projetos que poderiam ser implementados na área. De acordo com o histórico da ocupação do solo, Nascimento et al. (2010) assinala que a agricultura de café sombreado e silvibananeira foram as pioneiras atividades agrícolas da região, seguidas do turismo.
Atualmente, a área representa uma unidade de conservação APA, na qual não são admitidas plantações florestais para comércio. No entanto, plantios agroflorestais são permitidos.

Verifica-se que os projetos NZ ETS e VCS para floresta ombrófila apresentam um retorno líquido maior do que outros projetos que poderiam ser implementados na APA da Serra de Baturité (Tabela 4).

Deve-se ressaltar que os parâmetros econômicos aqui comparados são estimativas levantadas em outras regiões. Porém os cenários representam alternativas

Tabela 3. Fluxo de caixa dos três cenários avaliados.

Table 3. Cash flow in the three scenarios evaluated.

\begin{tabular}{|c|c|c|c|c|c|c|}
\hline \multirow{2}{*}{ Custos } & \multicolumn{6}{|c|}{ Ano } \\
\hline & 0 & 1 & 2 & 3 & 4 & 5 \\
\hline Construção de cerca & 520 & & & & & \\
\hline Custos de transação & 111 & & & & & \\
\hline Combate a formigas & 37 & & & & & \\
\hline Roçada & 209 & & & & & \\
\hline Adubação & 55 & & & & & \\
\hline Total ano-base & 933 & & & & & \\
\hline \multicolumn{7}{|l|}{ Manutenção } \\
\hline Limpeza de aceiros & & 40 & 40 & 40 & & \\
\hline Monitoramento $\mathrm{c} / 5$ anos & & & & & & 18 \\
\hline Total & & 40 & 40 & 40 & $\mathbf{0}$ & 18 \\
\hline \multicolumn{7}{|l|}{ Receitas } \\
\hline MDL & & 186 & 186 & 186 & 186 & 186 \\
\hline NZ ETZ & & 1.638 & 1.638 & 1.638 & 1.638 & 1.638 \\
\hline VCS & & 1.318 & 1.318 & 1.318 & 1.318 & 1.318 \\
\hline \multicolumn{7}{|l|}{ Renda líquida } \\
\hline MDL & -1.754 & -202 & -202 & -202 & -202 & -220 \\
\hline NZ ETZ & -1.754 & 1.249 & 1.249 & 1.249 & 1.249 & 1.231 \\
\hline OTC & -1.754 & 929 & 929 & 929 & 929 & 911 \\
\hline \multicolumn{7}{|l|}{ Resultados financeiros } \\
\hline Mercado & & MDL & NZ ETS & VCS & & \\
\hline Taxa de desconto & & 0,1 & 0,1 & 0,1 & & \\
\hline Idade de Rotação & & 30 & 30 & 30 & & \\
\hline Valor Líquido Presente & & $\mathrm{R} \$(702,50)$ & $\mathrm{R} \$ 1.336$ & $\mathrm{R} \$ 2.138$ & & \\
\hline Taxa Interna de Retorno & & - & $21 \%$ & $18 \%$ & & \\
\hline Valor Equivalente Anual & & $\mathrm{R} \$(-74,52)$ & $\mathrm{R} \$ 141,7$ & $\mathrm{R} \$ 226,9$ & & \\
\hline Valor Esperado da Terra & & $\mathrm{R} \$(-745,2)$ & $\mathrm{R} \$ 1.417$ & $\mathrm{R} \$ 2.269$ & & \\
\hline
\end{tabular}

Fonte: Tabela elaborada pelo autor com base em CI Florestas (2011)

Tabela 4. Análise econômica de rentabilidade em cinco cenários florestais da Mata Atlântica.

Table 4. Rentability Economic Analyses in three different Forest Project.

\begin{tabular}{lccc}
\multicolumn{1}{c}{ Cenário } & Fonte & VPL (R\$.ha) & TIR (\% a.a.) \\
Bananicultura & Embrapa (2004) & 2.084 & 14,87 \\
Café sombreado & Siqueira et al. (2011) & 546,81 & 12,65 \\
NZ ETS & Autor & 1.336 & 21 \\
VCS & Autor & 2.138 & 18 \\
\hline
\end{tabular}


de projetos que poderiam ser implantados na floresta ombrófila da Serra de Baturité.

\section{CONCLUSÕES}

A América Latina possui a segunda maior demanda mundial de projetos de carbono florestal. Somente no ano de 2013 foram transacionadas $19 \mathrm{MtCO} 2$ (StanleyPeters \& Gonzalez, 2014). No entanto, as estimativas de custos de produção e rentabilidade de serviços ambientais são pouco exploradas.

A APA da Serra de Baturité apresenta grande potencial de sumidouro de carbono, sequestrando em média 84,63 tCO2.ha ${ }^{-1}$. De acordo com os preços e custos de mercado para o ano de 2012, conclui-se que o projeto florestal para sequestro de carbono na APA da Serra de Baturité é viável nos mercados voluntários e inviável no mercado regulado. O projeto florestal da APA de Baturité é um exemplo de como projetos florestais podem ser usados na contribuição para a mitigação das mudanças climáticas.

Os custos de transação variam de acordo com a organização que faz a validação e verificação dos créditos de carbono e tendem a decrescer de acordo com o tamanho e a extensão do projeto. Esse fato inviabiliza a participação individual de pequenos produtores em projetos que visem a geração de créditos de carbono com características semelhantes aos cenários apresentados no presente trabalho.

O estudo apresentado pode servir como ponto de partida para avaliar outros projetos de redução de emissões de gases de efeito estufa. Porém Trigeorgis (1996) salienta que, sob incerteza, o valor futuro de uma variável é caraterizado por uma distribuição de variabilidade. Nesse caso a recomendação para trabalho futuro é modelar uma análise de sensibilidade que considere as possibilidades de riscos e incertezas.

\section{STATUS DA SUBMISSÃO}

Recebido: 7 out., 2013

Aceito: 30 mar., 2015

\section{AUTOR(ES) PARA CORRESPONDÊNCIA}

\section{Ana Milena Plata Fajardo}

Departamento de Engenharia Florestal, Universidade Federal do Paraná - UFPR, CEP 80210-170, Curitiba, PR, Brasil e-mail: aplatafa@gmail.com

\section{REFERENCIAS}

Baalman P, White M. 302 GHG accounting for forest and other land use projects [online]. GHG Institute; 2014. [citado 2014 jul. 01]. Disponível em: http://ghginstitute. org/product/301-ghg-accounting-for-forest-inventories/

Batista R, Bueno T. Sequestro de carbono em diferentes fitofisionomias do cerrado. SynThesis Revista Digital FAPAM 2010; 2(2): 127-143.

Brasil. Camâra dos Deputados. Projeto de lei no 4.425, de 2004. Dispõe sobre os incentivos fiscais a serem concedidos às pessoas físicas e jurídicas que invistam em projetos de Mecanismo de Desenvolvimento Limpo - MDL que gerem Reduções Certificadas de Emissões - RCEs, autoriza a constituição de fundos de investimento em projetos de MDL e dá outras providências [online]. 2004. [acesso 2011 abr. 23]. Disponível em: http://www.camara.gov.br/internet/ sileg/Prop_Detalhe.asp?id=269661

Brown S, Gillespie AJR, Lugo AE. Biomass estimation methods for tropical forests with applications to forest inventory data. Forest Science 1989; 35: 881-902.

Brown S. Measuring carbon in forests: current status and future challenges. Environmental Pollution 2002; 116(3): 363-372. http://dx.doi.org/10.1016/S0269-7491(01)002123. PMid:11822714.

Centro de Inteligência em Florestas - CI Florestas. Sistemas agroflorestais [online]. [acesso 2011 nov. 10]. Disponível em: http://www.ciflorestas.com.br/documentos.php?t=C

Empresa Brasileira de Pesquisa Agropecuária - Embrapa. O Cultivo da banana para o estado do Amazonas [online]. 2004. [acesso 2015 jun. 22]. Disponível em: http:// sistemasdeproducao.cnptia.embrapa.br/FontesHTML/ Banana/BananaAmazonas

Fernandes A, Salis S, Crispim S. Estoques de carbono do estrato arbóreo de cerrados no pantanal da Nhecolândia. Corumbá, MS: Embrapa; 2008. Comunicado Técnico n. 68.

Foody GM, Boyd DS, Cutler MEJ. Predictive relations of tropical forest biomass from landset TM data and their transferability between regions. Remote Sensing of Environment 2003; 85(4): 463-474. http://dx.doi. org/10.1016/S0034-4257(03)00039-7.

Galik CS, Jackson RB. Risks to forest carbon offset projects in a changing climate. Forest Ecology and Management 2009; 257(11): 2209-2216. http://dx.doi.org/10.1016/j. foreco.2009.03.017.

Graça LR, Rodigheri HR, Conto AJ. Custos florestais de produção: conceituação e aplicação. Colombo: Embrapa Florestas; 2000. 32 p. Documentos n. 50.

Intergovernmental Panel on Climate Change - IPCC. Guidelines for national greenhouse gas inventories. Japan: IGES; 2006.

Kulshreshtha SN, Lac S, Johnston M, Kinar C. Carbon sequestration in protected areas of canada: an economic 
valuation. Canadá: Canadian Parks Council; 2000. Economic Framework Project n. 549.

Lacerda JS, Couto HTZ, Hirota MM, Pasishnyk N, Polizel JL. Estimativa da biomassa e carbono em áreas restauradas com plantio de essências nativas. Emendabis Mensvram Silvarvm 2009; (5): 1-23.

Lile R, Powell M, Toman M. Implementing the clean development mechanism: lessons form the U.S. private sector participation in activities implemented jointly. Washington DC: Resources for the Future Discussion; 1998. Discussion Paper n. 99-08.

Lima VB Jr, Rezende JLP, Oliveira AD. Determinação da taxa de desconto a ser usada na análise econômica de projetos florestais. Revista Cerne 1997; 3(1): 45-66.

Ministry for the Environment. Climate change information [internet]. [acesso 2013 mar. 11]. Disponível em: http:// www.climatechange.govt.nz/emissions-trading-scheme/ participating/forestry/

Nascimento FR, Souza MJN, Cruz MLB. Diagnóstico socioeconômico da área de proteção ambiental. Espaço Geográfico em Análise 2010; (20): 19-33.

Oliveira TS, Araújo FS. Historico dos impactos antrópicos e aspectos geoambientales. In: Oliveira TS, Araújo FS, editores. Diversidade e conservação da biota na Serra de Baturité. Fortaleza: Edições UFC:COELCE Editora; 2005.

Pearson TRH, Brown S, Sohngen B, Henman J, Ohrel S. Transaction costs for carbon sequestration projects in the tropical forest sector. Mitigation and Adaptation Strategies for Global Change 2014; 19(8): 1209-1222. http://dx.doi. org/10.1007/s11027-013-9469-8.

Rezende JLP, de Oliveira AD. Análise econômica e social de projetos florestais. Viçosa: UFV; 2001.389 p.

Ronquim CC. Dinâmica espaço temporal do carbono aprisionado na fitomassa dos agroecossistemas no nordeste do Estado de São Paulo. Campinas: Embrapa Monitoramento por Satélite; 2007. 52 p. Documentos n. 63.

Salati E. Emissão x seqüestro de CO2 - uma nova oportunidade de negócios para o Brasil. In: Anais do Seminário emissão $x$ sequestro de CO2 - uma nova oportunidade de negócios para o Brasil; 1994; Rio de Janeiro. Rio de Janeiro: CVRD; 1994. p. 15-37.
Saldarriaga JG, West DC, Tharp ML, Uhl C. Long-term chronosequence of forest succession in the upper Rio Negro of Colombia and Venezuela. Journal of Ecology 1988; 76(4): 938-958

Santos E. Administração financeira da pequena e médiana empresa. São Paulo: Atlas; 2001.

Simioni FJ, Hoeflich VA. Avaliação de risco em investimentos florestais. Boletim de Pesquisas Florestais 2006; (52): 79-92.

Singh G. Understanding carbon credits. New Delhi: Aditya Books; 2009466 p.

Siqueira HM, Souza PM, Ponciano NJ. Café convencional versus café orgânico: perspectivas de Sustentabilidade socioeconômica dos produtores familiares do Espírito Santo. Revista Ceres 2011; 58(2): 155-160.

Souza CL, Ponzoni FJ. Avaliação de índices de vegetação e de bandas TM/LANDSAT para estimativa de volume de madeira em floresta implantada de Pinus spp. In: Anais IX do Simposio Brasileiro de Sensoriamento Remoto; 1998; Santos. Santos: INPE; 1998. p. 1537-1547.

Stanley-Peters M, Gonzalez, G. Sharing the stage state of the voluntary carbon markets. a report by forest trends ecosystem marketplace \& bloomberg new energy finance. Washington, DC: Ecosystem Marketplace; 2014.

Stanley-Peters M, Yin D. Maneuvering the mosaic: state of the voluntary carbon markets 2013. Washington, DC: Ecosystem Marketplace; 2013.

Trigeorgis L. Real options: managerial flexibility and strategy in resource allocation. Cambridge, MA: MIT Press; 1996.427 p.

United Nations Framework Convention on Climate Change - UNFCCC. Progress in the development of guidance materials, standards and reporting guidelines for terrestrial observing systems for climate. Bali: UNFCCC; 2007.

Watzlawick LF. Estimativa de biomassa e carbono em floresta ombrófila mista e plantações florestais a partir de dados de imagens do satélite IKONOS II [tese]. Curitiba: Setor de Ciências Agrárias, Universidade Federal do Paraná; 2003.

Yu CM. Sequestro florestal de carbono no Brasil: dimensões políticas, socioeconômicas e ecológica. São Paulo: Annablume; 2004. 